\title{
Mobility of Chernobyl ${ }^{137} \mathrm{Cs}$ in undisturbed soil: Analysis methods and techniques
}

\author{
K.G. Andersson, C.L. Fogh and J. Roed
}

Risoe National Laboratory, 4000 Roskilde, Denmark

\begin{abstract}
The mobility of ${ }^{137} \mathrm{Cs}$ in soil is an important factor governing doses received after a major nuclear accident as well as the effect of many countermeasures for mitigation. A set of simple procechures for the cetermination of factors influencing the soil ${ }^{137} \mathrm{Cs}$ mobility have been suggested and described $A$ number of tests have been carried out on field samples to demonstrate the validity and reproducibility of the procedures.
\end{abstract}

\section{INTRODUCTION}

The mobility of radiocaesium (notably ${ }^{137} \mathrm{Cs}$ ) in soil is a cnucial parameter influencing both external and internal doses received after a major nuclear accident affecting large areas of land. The mobility of radiocaesium in soil may vary widely, depending on a host of factors, including time, the physicochemical form of the contaminants, and the soil characteristics. During the period of the Chemobyl accident Bobovnikova et al. [1] found that deposition of insoluble particle forms of radiocaesium was predominant at a distance of $18 \mathrm{~km}$ from the Chemobyl plant. The bioavailability of this contamination was found to be relatively low [2]. At large distances, soluble forms were most common, although relatively small fractions of not readily soluble caesium particles were measured on air filter samplers as far away as Prague [3]. Dependent on chemical conditions in the soil, particle weathering will lead to a delayed mobilisation of caesium contamination in the soil. In the soil, particularly some micaceous minerals have the ability to very strongly bind and immobilise ionic caesium, in regions between unit layers, to which larger, hydrated ions are physically prevented from entering $[4,5,6]$.

Knowledge of the mobility of radiocaesium in soil is not only important in connection with dose assessments. If factors influencing contaminant mobility are ignored, some potentially effective methods for reduction of both internal and external dose may have very little beneficial effect $[7,8]$.

This paper describes a series of relatively simple methods that can be applied to investigate into the mobility of radiocaesium in soil. These methods have been tested on samples collected during field campaigns to areas contaminated by the Chernobyl accident, in the former Soviet Union and in Sweden.

\section{METHODS}

For identification of the current extent of migration of radiocaesium in the soil, a precise soil core sampling technique has been described [9], involving sealing of the cores in plastic tubes and deep freezing prior to slicing using a diamond saw. Gamma analysis of the soil core only provides momentary information on the vertical radiocaesium distribution in the soil. To obtain an image of the possible changes to the radiocaesium distribution in soil as well as to examine the radiocaesium bioavailability, it is necessary to make further investigations. An assessment of the soil $\mathrm{pH}$ may give information on, e.g., the chemical conditions in the soil with respect to particle weathering, and further, it is known that the organic cation exchange capacity of the soil decreases with the soil $\mathrm{pH}$ [10]. The potential significance of the organic matter can be evaluated after an examination of the organic content in the vertical soil profile. This can for instance be carried out by measuring the weight loss by ignition of samples at $360^{\circ} \mathrm{C}$ relative to drying at $105^{\circ} \mathrm{C}$.

Textural analyses may be an important means of obtaining information about the conditions for radiocaesium fixation in the soil. Although the fine-grained 'clay' fraction may contain many different types of minerals, it would contain the small micaceous minerals, which are capable of strongly binding 
and retaining caesium ions. A simple method is suggested for an estimate of texture, based on a technique used at the University of Hew Hampshire [11]. Prior to the analysis all organic matter must have been removed. If the organic matter content of the soil is relatively small, so that the ash content will not distort the further analysis (by adding to the fine-grained particle fraction), this may be accomplished by ignition as described above. First, the soil particle fraction greater than $2 \mathrm{~mm}$ is removed by sieving. A $50 \mathrm{ml}$ glass tube is filled with $15 \mathrm{ml}$ of soil sample. The tube is tapped at the bottom to ensure compaction of the sample and removal of any air spaces. Then $1 \mathrm{ml}$ of a $10 \%$ solution of the dispersing agent sodium hexametaphosphate $\left(\mathrm{Na}(\mathrm{n}+2) \mathrm{P}_{\mathrm{n}} \mathrm{O}_{(3 \mathrm{n}+1)}, \mathrm{n}=9-15\right)$ is added to disperse the soil particles, and the tube is filled with distilled water to the $45 \mathrm{ml}$ mark. The tube is then capped and shaken for at least five minutes to mix the soil and water. Then the tube is placed in a stand for 30 seconds, and the solution part is decanted into another $50 \mathrm{ml}$ tube, where it is left undisturbed for 30 minutes. The solution part from this tube is then decanted into a third $50 \mathrm{ml}$ tube. The contents of the first two tubes, containing respectively the sand and silt fractions, can now be read on the volume scale on the tubes. The clay fraction, however, will generally be too fine-grained to settle in the tube, but may, according to the New Hampshire technique be calculated by subtracting the measured sand and silt volumes from the volume of the total sample. Obviously, the often small clay volume will not be very accurately defined by this method, which only has relevance for rough classification of the soil according to textural classes.

Apart from the simplicity and little time-consumption (i.e., low cost), this type of analysis, however, has an important advantage compared with, c.g., the widely applied hydrometer method [12] in that the fractions are physically separated. This enables gamma spectrometric analysis of the radiocaesium content in the various textural fractions, which will give a very useful indication of the likely mechanisms of radiocaesium binding in the soil. However, as the small clay fraction is generally expected to contain a comparatively large part of the radiocaesium, it is crucial that the fractions are separated correctly, so that small soil particles trapped in the liquid between larger precipitated soil particles are released. Therefore, it was decided to extend the method so that the precipitation procedures described above are repeated for both the 'sand' and the 'silt' parts of the sample, until no significant further releases of 'clay' sized material are observed. Repeated analyses for different soils showed that after four repetitions of each stage of the precipitation procedures, further releases of 'clay' sized material were generally insignificant ( $3 \%$ of total 'clay' sized fraction). Figure 1 shows a typical example of relative mass fractions of clay released from the sand and silt fractions of a soil sample by repeated precipitation. In the four clay fractions, the distribution of radiocaesium was found to exactly match the distribution of clay mass.

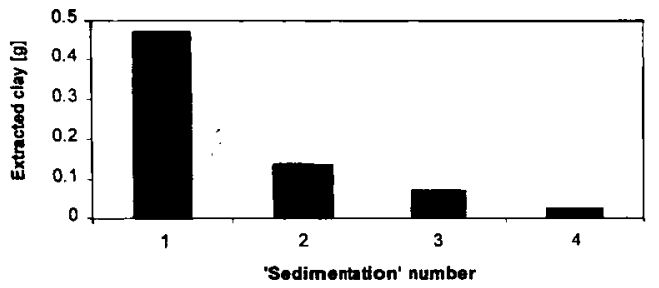

Figure 1. Typically observed relative fractions of 'clay' sized particles extracted from a soil sample after repeated precipitations (sedimentation) of the larger particles in the sample. The mass of the whole soil sample was here $15.23 \mathrm{~g}$ - 
The fractions that had not precipitated (the 'clay' part) are then subjected to evaporation at $95{ }^{\circ} \mathrm{C}$ overnight, and the dried sample is subsequently carefully transferred into a weighed dry Petri dish, with the use of as little water as possible. The 'clay' size fraction is here dried overnight at $50^{\circ} \mathrm{C}$. After a further 24 hours in a desiccator, the samples are weighed to obtain a better measure of the 'clay' sized fraction of the samples. Prior to drying it may be necessary to reduce the surface tension, to obtain homogeneous settling of the particles in a suitable geometry for gamma analysis. This can be accomplished by adding a droplet of diluted dishwashing detergent to the sample. If the 'clay' layer in the bottom of the Petri dish is very thin, flakes of it may come under strong influence of static electricity, distorting the sample geometry prior to counting. To avoid this, a filter paper may be applied to cover the sample after weighing. Finally, the samples are wrapped in thin plastic film and analysed in a leadshielded germanium crystal detector system.

Sequential chemical extractions on a soil sample (typically ca. 2 g) can give indications of both the strength and to some degree the type of binding of the radiocaesium. For this purpose, a suitabie method has been developed on the basis of the technique described by Tessier et al. [13]. The first of the sequential extractions is performed with a $1 \mathrm{M}$ solution of ammonium acetate (at $\mathrm{pH} 7$ ), to determine the readily exchangeable fraction of the radiocaesium contamination. For the second sequential extraction a mild reducing solution of hydroxylamine hydrochloride $(0.04 \mathrm{M}$ at $\mathrm{pH} 2)$ is used. The third sequential extraction utilises a $30 \%$ hydrogen peroxide solution (adjusted to $\mathrm{pH} 2$ with nitric acid). This will oxidise the organic soil fraction, and release organic held contaminants to the solution. The hydrogen peroxide technique would also be expected to have a considerable oxidising effect on, e.g., fuel particles, if present, thus mobilising contained radiocaesium. The fourth sequential extraction is performed using 7 $M$ nitric acid, to extract a fraction of comparatively strongly mineral bound radiocaesium. However, usually, a rather large fifth fraction of the radiocaesium remains in the sample even after subjection to this type of extraction. The whole sequential extraction technique is described in greater detail by Andersson \& Roed [5]. The technique can be applied on 'discs' representing layers in a vertical soil profile and give information on vertical differences in soil composition and radiocaesium fixation, which may result in different migration rates at different depths in the soil. Also the strength of radiocaesium binding in the different individual textural fractions may be assessed by the sequential extraction procedure, if the clay content is sufficient to enable the analysis. This could for instance reveal differences between degrees of fixation in the 'clay'-sized mineral compositions of different soils. As the dehydration between unit layers of micaceous minerals generally takes place between $450^{\circ} \mathrm{C}$ and $550^{\circ} \mathrm{C}$ [14], ignition at $360^{\circ} \mathrm{C}$ should not significantly affect mineral binding mechanisms.

Neutron activation analysis can give valuable information on concentrations in the soil of relevant stable isotopes. For instance, it is known that scandium $\left({ }^{45} \mathrm{Sc}\right)$ is ubiquitous in soils, and is a good tracer for clay minerals [15]. Both ${ }^{45} \mathrm{Sc}$ and the naturally occurring caesium isotope, ${ }^{133} \mathrm{Cs}$, have relatively large neutron absorption cross-sections and have long-lived activation products, facilitating neutron activation analysis. Radiocaesium will, particularly in the early phase after an accident, be present in the soil in other physico-chemical forms [5] than the often very strongly mineral-bound stable caesium. However, the distribution of the naturally occurring caesium isotope throughout the various soil layers can give information on the progress of ${ }^{137} \mathrm{Cs}$ towards a dynamic equilibrium in the various parts of the soil [16], and is thereby useful for the prediction of future developments in the ecosystem. Differences between current mobility/bioavailability of ${ }^{137} \mathrm{Cs}$ and that of ${ }^{133} \mathrm{Cs}$ can be examined by comparing ${ }^{137} \mathrm{Cs}$ results of the sequential extraction technique with ${ }^{133} \mathrm{Cs}$ content of the same fractions, measured by neutron activation analysis. Differences in strength of fixation of ${ }^{133} \mathrm{Cs}$ and ${ }^{137} \mathrm{Cs}$ in soil at various distances from Chemobyl may also indicate the significance of the presence of hot particles. The procedure applied for neutron activation analysis is to dry the soil at ca. $70^{\circ} \mathrm{C}$ and $\mathrm{grind} / \mathrm{mix}$ it in a mortar prior to taking out a ca. $0.15 \mathrm{~g}$ sample. The sample is placed in a polyethylene container and irradiated for ca. 2 hours in a neutron flux of $4 \cdot 10^{17} \mathrm{n} \mathrm{m}^{-2} \mathrm{~s}^{-1}$. 


\section{RESULTS AND DISCUSSION}

The results presented in this paper are aimed at verifying the validity and demonstrating the usefulness of the applied techniques for analysis of radiocaesium mobility in soil. A full account of the application of the techniques on samples of soil contaminated by the Chernobyl accident, taken from a total of 10 selected locations within the former Soviet Union, at distances from 10 to $220 \mathrm{~km}$ from the power plant and from 5 relatively highly contaminated locations in Sweden will be given at a later date.

A series of samples from two different fields [5] in Gävle, Sweden, were subjected to the texture analysis procedure described above (with four 'clay' precipitations). Identical samples were analysed using the standard hydrometer method, and all figures were found to be consistent within $20 \%$.

To test the consistency and reproducibility of the sequential extraction procedure it was applied on five topsoil samples taken in 1996 in the same 'undisturbed' field in Gävle (within a $2 \mathrm{~m}$ by $2 \mathrm{~m}$ square), contaminated by ca. $200 \mathrm{kBq} \mathrm{m}$ of ${ }^{-2}{ }^{137} \mathrm{Cs}$ from the Chernobyl accident (see Figure 2). In the least significant of the extracted fractions (1-3), the recorded ${ }^{137} \mathrm{Cs}$ results showed a standard deviation of ca. $20 \%$. Due to the not very strong contamination of the samples the gamma counting on each of these fractions was alone associated with a standard deviation of ca. $8 \%$. In the two most significant fractions (4 and 5) results were associated with standard deviations of respectively 2.3 and $6 \%$, and standard deviations on the gamma counting alone were here respectively 1.3 and $2 \%$. The small variation also indicates a horizontal homogeneity in the binding pattern of radiocaesium in the top layer of the examined square although about 10 years had passed from the Chernobyl accident to the sampling time.

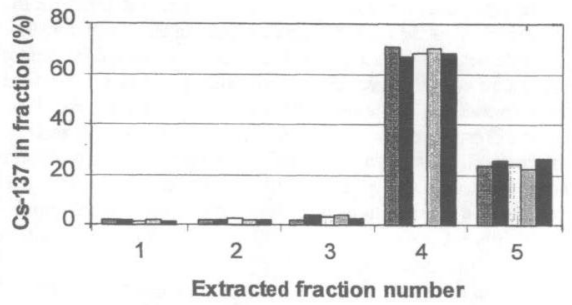

Figure 2. Sequential extraction results on five topsoil samples taken in Gavle, Sweden in 1996. Four extractions were performed as described above. The fifth fraction is the residue in the soil sample.

A general conclusion can be made on comparison of results obtained by two of the described techniques. A significant correlation $\left(R^{2}=0.7\right)$ was found between the ${ }^{137} \mathrm{C}$ s content in the 'clay' sized texture fraction and the fraction of ${ }^{137} \mathrm{Cs}$ remaining in the residual part of the sample after the four sequential extractions (see Figure 3). This correlation is surprisingly high considering that the examined samples represent different layers in the top $0-10 \mathrm{~cm}$ horizon of a wide variety of soil types (mostly sandy loams or loamy sands) covering a vast area from only few $\mathrm{km}$ away from the Chernobyl power plant to Sweden. The result can be seen as a verification of the efficiency of the method for separating texture fractions. The ${ }^{137} \mathrm{Cs}$ content of the 'clay' sized texture fraction was found to have no correlation with the $4^{\text {th }}$ sequential extraction fraction (by nitric acid) nor with the sum of the $4^{\text {th }}$ extraction fraction and the residue. The slope being close to unity indicates that the strongly bound ${ }^{137} \mathrm{Cs}$ residue after the sequential extractions corresponds to the part of the ${ }^{137} \mathrm{Cs}$ that is selectively fixed in micaceous minerals, whereas 
the more loosely bound ${ }^{137} \mathrm{Cs}$ is distributed over the large surfaces provided by the various soil constituents.

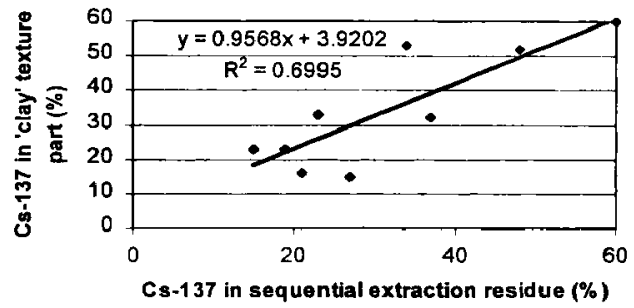

Figure 3. Fraction of ${ }^{137} \mathrm{Cs}$ in the 'clay' sized texture part versus fraction of ${ }^{137} \mathrm{Cs}$ in the residue after 4 sequential extractions, on 9 soil samples taken in the former Soviet Union and in Sweden about 10-13 years after the Chernobyl accident.

Figure 4 shows some results of neutron activation analysis performed on soil samples. As scandium can be regarded as a tracer for mineral (clay) soil components, it is not surprising that the ${ }^{45} \mathrm{Sc}$ content in a highly organic soil taken at Savichi, Russia is more than a factor of 10 less than that in for instance a sandy loam in Sweden. The scandjum content in the Savichi sample is also much less than what was measured in other samples from the former Soviet Union, although the scandium content in the Swedish samples is generally higher than that in the samples from the former Soviet Union. The very strong correlation between contents of scandium and stable caesium indicates the strong affinity of certain clay minerals in the examined soils for fixation of caesium. It should be mentioned that some of the samples represent highly organic soil horizons. In the long run, when any possible ${ }^{137} \mathrm{Cs}$ association with particles and colloids becomes negligible, and ${ }^{137} \mathrm{Cs}$ migration into mica interlayer sites has progressed, the degree of fixation of ${ }^{137} \mathrm{Cs}$ would in the particular type of soil be expected to be similar to that of ${ }^{133} \mathrm{Cs}$.

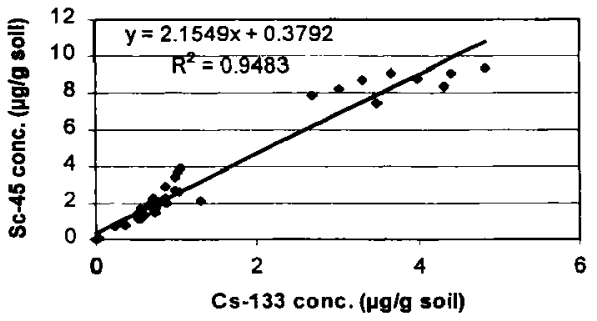

Figure 4. ${ }^{45} \mathrm{Sc}$ concentrations versus ${ }^{133} \mathrm{Cs}$ concentrations in 36 soil samples from 15 different locations in the former Soviet Union and Sweden. 


\section{CONCLUSIONS}

A series of simple methods for analysis of the mechanisms and degrees of radiocaesium fixation in undisturbed soil samples are described. A series of tests have been conducted to examine the validity of results obtained by some of the methods. The reproducibility of the sequential extraction procedure, which involves the most complicated laboratory procedures, was found to be satisfactory, even when applied to a not very strongly contaminated Swedish soil sample. Results obtained with the suggested technique for texture determination were found to be in-line with results obtained using standard technique. The ${ }^{137} \mathrm{Cs}$ content of 'clay'-sized texture fractions was found to be correlated with the strongest bound ${ }^{137} \mathrm{Cs}$ fraction measured by the sequential extraction technique, validating the texture determination method and suggesting that the sequential extraction technique isolates the strong selectively mica-bound caesium in its fifth fraction. Neutron activation analysis showed ${ }^{133} \mathrm{Cs}$ and ${ }^{45} \mathrm{Sc}$ to be associated with the same soil components (mica), indicating the likely final destiny of ${ }^{137} \mathrm{Cs}$ in soil. This can be further examined using neutron activation analysis to investigate the stable element distribution in sample fractions separated by sequential chemical extractions.

\section{References}

I C.I. Bobovnikova, K.P. Machonko, A.A. Siverina, F.A. Rabotna, V.P. Gutareva, A.A. Volokitin, Atomnaya Energiya 71, p.449 (1991) (as referenced by Tomasek et al., J. Radioanalytical Nucl. Chem. letters 201 (5), pp. 409-416, 1995).

2 P.F. Bondar, Yu. A. Ivanov, A.G. Ozomov, in The Radiobiological Impact of Hot Beta-Particles from the Chernobyl fallout: Risk assessment, IAEA, Vienna, pp. 58-67 (1992).

3 M. Tomasek, K. Rybacek, L. Wilhelmova, J. Radioanalytical Nucl. Chem. letters 201 (5), pp. $409-41$ (1995).

4 B.L. Sawhney, Soil Sci. Soc. Am. Proc 31, pp. 181-183 (1967).

5 K.G. Andersson, J. Roed, J. Environ. Radioactivity 22, pp. 183-196 (1994).

6 A.B. Hird, D.L. Rimmer, F.R. Livens, J. Environ. Radioactivity 26, pp. 103-118 (1995).

7 J. Roed, C. Lange, K.G. Andersson, H. Prip, S. Olsen, V.P. Ramzaev, A.V. Ponomarjov, A.N. Barkovsky, A.S. Mishine, B.F. Yorobiev, A.V. Chesnokov, V.N. Potapov, S.B. Shcherbak, Decontamination in a Russian Settlement, Report Riso-R-870(EN), Risoe National Laboratory (1996).

8 K.G. Andersson, A. Rantavaara, J. Roed, K. Rosén, B. Salbu, L. Skipperud, A Guide to Countermeasures for Implementation in the Event of a Nuclear Accident Affecting Nordic FoodProducing Areas, Report NKS-16, Nordic Nuclear Safety Research (2000).

9 J. Roed, O. Togawa, in Proceedings of IRPA9 - 1996 International Congress on Radiation Protection, LAEA, Vienna, Austria, pp. 666-668 (1996).

10 N.S. Brady, The Nature and properties of soils, $8^{\text {th }}$ edn., Macmillan Publishing Co. Inc., New York (1970).

11 University of New Hampshire, Spaulding Life Center, Durham, New Hampshire, USA, Analytical Services Lab Procedures web-site (http://aslan.unh.edu/procedures) (2001).

12 American Society for Testing Materials, Designation D 422-54 T, pp. 1756-1766 (1954).

13 A. Tessier, P.G.C. Campbell, M. Bisson, Analytical Chemistry 51, pp. 220-227 (1979).

14 F.M. Wahl, Am. Ceramic Soc. 44, pp. 676-68! (1965).

15 U. Sansone, M. Belli, M. Riccardi, A. Alonzi, Z. Jeran, J. Radojko, B. Smodis, M. Montanari, F. Cavolo, The Science of the Total Environment 219, pp. 21-28 (1998).

16 D.H. Oughton, J.P. Day, Journal of Radioanalytical and Nuclear Chemistry, Articles, 174, pp. 177185 (1993). 